\title{
PRODUÇÃO DE PROTEASES POR Bacillus SP SMIA-2 CRESCIDO EM SORO DE LEITE E ÁGUA DE MACERAÇÃO DE MILHO E COMPATIBILIDADE DAS ENZIMAS COM DETERGENTES COMERCIAIS ${ }^{1}$
}

\author{
Wellingta Cristina Almeida do NASCIMENTO², Meire Lelis Leal MARTINS²,*
}

\begin{abstract}
RESUMO
A produção de proteases por Bacillus sp. SMIA-2 cultivado em um meio de cultura contendo soro de leite e água de maceração de milho foi estudada. Além disso, a compatibilidade da enzima com detergentes comerciais foi também avaliada. A atividade máxima da enzima (70 U/mg proteína) foi observada na fase estacionária de crescimento, com 32 h de incubação. Estudos sobre a caracterização da protease revelaram que a temperatura ótima para atividade desta enzima foi $70{ }^{\circ} \mathrm{C}$ e que a mesma manteve $91 \%$ de sua atividade quando incubada a $70^{\circ} \mathrm{C}$ na presença do cálcio. O valor ótimo de $\mathrm{pH}$ encontrado para a protease foi 8,0 , sendo que a enzima manteve $85 \%$ e $46 \%$ de sua atividade quando incubada por $1 \mathrm{~h} \mathrm{em} \mathrm{pH} 9$ e pH 10 respectivamente. A protease manteve $64 \%$ e $50 \%$ de sua atividade quando incubada a $70{ }^{\circ} \mathrm{C}$ por $30 \mathrm{~min}$ com os detergentes $\mathrm{Cheer}^{\circledast} \mathrm{e}$ Tide $^{\circledast}$ respectivamente. A utilização da glicina juntamente com íons cálcio resultou em um aumento da estabilidade enzimática em todos os detergentes testados. Em presença dos detergentes Ultra bizz ${ }^{\circledR}$, Cheer ${ }^{\circledast}$ e Tide $^{\circledast}$, a enzima manteve aproximadamente $100 \%$ de atividade, após 30 min de incubação a $70{ }^{\circ} \mathrm{C}$.

Palavras-chave: proteases, soro de leite, detergentes comerciais, Bacillus sp.
\end{abstract}

\section{SUMMARY}

PRODUCTION OF PROTEASES BY Bacillus sp. SMIA-2 GROW ON WHEY AND CORN STEEP LIQUOR AND COMPATIBILITY OF THE ENZYME WITH COMMERCIAL DETERGENTS. The production of protease by the thermophilic Bacillus sp. SMIA-2 cultivated in a medium containing whey and corn steep liquor was studied. In addition, the compatibility of the enzyme with commercial detergents was evaluated. The maximum activity of the enzyme $(70 \mathrm{U} / \mathrm{mg}$ protein) was observed in the phase stationary of growth, with $32 \mathrm{~h}$ of incubation.

Studies on the protease characterization revealed that the optimum temperature of this enzyme was $70{ }^{\circ} \mathrm{C}$ and that it maintained $91 \%$ of its activity when incubated a $70{ }^{\circ} \mathrm{C}$ in the presence of calcium. The optimum pH of the enzyme was found to be 8.0 and the enzyme maintained $85 \%$ and $46 \%$ of its original activity when incubated for $1 \mathrm{~h}$ at pH 9 and pH 10 respectively. Protease retained $64 \%$ and $50 \%$ of its activity after $30 \mathrm{~min}$ incubation at $70{ }^{\circ} \mathrm{C}$ in presence of the detergents Cheer ${ }^{\oplus}$ and Tide ${ }^{\circledast}$ respectively. The addition of glycine and calcium improved the stability of the enzyme in all detergents used. In the presence of the detergents Ultra bizz ${ }^{\circledast}$, Cheer ${ }^{\circledR}$ and Tide ${ }^{\circledR}$, the enzyme maintained $100 \%$ of its activity after $30 \mathrm{~min}$ of incubation at $70^{\circ} \mathrm{C}$.

Keywords: proteases, milk whey, commercial detergents, Bacillus sp.

\section{1 - INTRODUÇÃO}

As proteases constituem um dos mais importantes grupos de enzimas industriais e têm aplicação em diferentes indústrias, como de alimentos, têxtil, farmacêutica e de detergentes [23, 18, 12, 15]. Estas enzimas são responsáveis por $30 \%$ do total de enzimas produzidas no mundo [26].

As enzimas proteolíticas termoestáveis, produzidas por microrganismos do gênero Bacillus, são o grupo mais importante de enzimas produzidas comercialmente [29], sendo sua aplicação predominante (35\%) na indústria de detergentes [3,4].

Proteases são utilizadas em todos os tipos de detergentes, inclusive naqueles utilizados em máquinas automáticas de lavagem, e sua função é a degradação de compostos

\footnotetext{
${ }^{1}$ Recebido para publicação em 10/5/2005. Aceito para publicação em 6/7/2006 (001551)

${ }^{2}$ Centro de Ciências e Tecnologias Agropecuárias,

Universidade Estadual do Norte Fluminense,

Av. Alberto Lamego, 2000, CEP 28015-620,

Campos dos Goytacazes, RJ, Brasil,

E-mail:meire@uenf.br

* A quem a correspondência deve ser enviada
}

tipicamente proteináceos, como sangue, manchas de ovos e leite. Até o presente momento, menos de 15 moléculas diferentes de enzimas são utilizadas em todo o mundo na indústria de detergentes. Essas enzimas são originárias de microrganismos, entre eles $B$. amyloliquefaciens, $B$. licheniformis, B. clauseii, B. lentus, B. alkaliphilicus e B. haloduram [19].

A utilização de proteases em formulações de detergentes requer que estas enzimas possuam elevada atividade $\mathrm{e}$ estabilidade em uma ampla faixa de $\mathrm{pH}$ e temperatura, que sejam efetivas em baixas quantidades $(0,4-0,8 \%)$ e compatíveis com vários detergentes comerciais [17].

Estima-se que por volta de $30-40 \%$ do custo envolvido na produção de proteases esteja relacionado ao meio de cultura utilizado para o crescimento do microrganismo. Portanto, sua otimização é de grande importância para a redução dos custos de produção [14].

Recentemente, vários resíduos agroindustriais têm sido usados como substratos para a produção de enzimas, devido à disponibilidade local e por representar uma fonte alternativa de baixo valor comercial, principalmente quando se visa à produção destas enzimas em larga escala. O soro de 
leite, por exemplo, é um resíduo altamente rico em proteínas, respondendo por $20 \%$ das proteínas encontradas no leite [27]. A sua utilização como substrato biotecnológico para produção de enzimas, poderia contribuir em muito para a redução do custo operacional da produção, bem como para a preservação do meio ambiente [17].

A água de maceração de milho também é considerada uma fonte de nutrientes relativamente barata e satisfatória para a produção de vários compostos [25]. Além de beneficiar o meio de crescimento pelo fornecimento de fonte de nitrogênio, este resíduo fornece vários micronutrientes, vitaminas e fatores estimulantes do crescimento microbiano [17].

O presente trabalho teve como objetivo avaliar a utilização do soro de leite e da água de maceração de milho como substratos para a produção de proteases por um microrganismo termofílico, Bacillus sp. SMIA-2. Algumas propriedades bioquímicas da enzima e sua compatibilidade com detergentes comerciais foram investigadas.

\section{2 - MATERIAL E MÉTODOS}

\section{1 - Microrganismo e condições da cultura}

O microrganismo utilizado neste estudo foi uma bactéria termofílica, Bacillus sp. SMIA-2, isolada por NUNES \& MARTINS [21].

Para a produção da protease o seguinte meio de cultura foi utilizado: Soro de leite em pó (70\% proteína, 15\% lactose, $2 \%$ gordura, $10 \%$ sais minerais e $3 \%$ umidade) - 1,0 g; água de maceração de milho (Sigma-Aldrich) - 5,0 g; $\mathrm{MgSO}_{4}$ - 0,5 g; $\mathrm{K}_{2} \mathrm{HPO}_{4}$ - 0,9 g; $\mathrm{KCl}$ - 0,3 g; $\mathrm{CaCl}_{2}$ - 0,3 g e traços de metais $\left(\mathrm{ZnO}-2,5 \times 10^{-3} \mathrm{~g} ; \mathrm{FeCl}_{3} \cdot 6 \mathrm{H}_{2} \mathrm{O}-2,7 \times 10^{-2} \mathrm{~g} ; \mathrm{MnCl}_{2} \cdot 4 \mathrm{H}_{2} \mathrm{O}-1,0 \mathrm{x}\right.$ $10^{-2} \mathrm{~g} ; \mathrm{CuCl}_{2} \cdot 2 \mathrm{H}_{2} \mathrm{O}-8,5 \times 10^{-4} \mathrm{~g} ; \mathrm{CoCl}_{2} \cdot 6 \mathrm{H}_{2} \mathrm{O}-2,4 \times 10^{-3} \mathrm{~g}$; $\mathrm{NiCl}_{3} \cdot 6 \mathrm{H}_{2} \mathrm{O}-2,5 \times 10^{-4} \mathrm{~g} ; \mathrm{H}_{3} \mathrm{BO}_{3}-3,0 \times 10^{-4} \mathrm{~g}$; e $\mathrm{Na}_{2} \mathrm{MoO}_{4}-$ $1,0 \times 10^{-3} \mathrm{~g}$ ), dissolvidos em $1 \mathrm{~L}$ de água destilada. $\mathrm{O} \mathrm{pH}$ foi ajustado para $7,5 \mathrm{com} 1,0 \mathrm{M} \mathrm{NaOH}$ e este meio foi esterilizado em autoclave a $121 \pm 2{ }^{\circ} \mathrm{C}$ por $15 \mathrm{~min}$.

O meio de produção foi inoculado com $1 \mathrm{~mL}$ de uma cultura de véspera e incubada em um agitador Thermo Forma Orbital Shaker (Ohio, USA) a $150 \mathrm{rpm}$ em temperatura de $50{ }^{\circ} \mathrm{C}$ por $60 \mathrm{~h}$. Os experimentos foram realizados com três repetições, sendo cada uma delas constituída por $50 \mathrm{~mL}$ de meio de cultura em erlenmeyer de $250 \mathrm{~mL}$. A intervalos de tempo determinados, foram retirados frascos para medida da densidade ótica a $600 \mathrm{~nm}$, com a utilização de um espectrofotômetro Hitachi modelo U-2000, pH e dosagem da atividade da enzima nos filtrados da cultura.

\section{2 - Ensaio enzimático}

Para a remoção das células, o meio de cultura foi centrifugado a $4500 \mathrm{~g}$ por $15 \mathrm{~min}$ a $4{ }^{\circ} \mathrm{C}$ em uma centrífuga modelo Hermle $Z 382$, e o sobrenadante livre de células, utilizado para dosagem da atividade da enzima.

A atividade enzimática foi determinada em triplicata pela quantificação de peptídeos solúveis em ácido tricloroacético (TCA) $15 \%$. O substrato utilizado para essa determinação foi uma solução de azocaseína $0,2 \%(\mathrm{p} / \mathrm{v})$ preparada em tampão TRIS/HCl ( $\mathrm{pH} \mathrm{8,5).} \mathrm{Foi} \mathrm{adicionado} \mathrm{0,5} \mathrm{mL} \mathrm{do} \mathrm{extrato}$ enzimático em 1,0 mL do substrato e incubado em banhomaria a $70^{\circ} \mathrm{C}$ por $10 \mathrm{~min}$. A reação foi paralisada pela adição de $0,5 \mathrm{~mL}$ de TCA e a solução, centrifugada a $15000 \mathrm{~g}$ por 5 min a $4{ }^{\circ} \mathrm{C}$ (Hermele $Z 382 \mathrm{~K}$ ). O mesmo procedimento foi realizado com o controle, exceto que o TCA foi adicionado antes do extrato enzimático [13].

Uma unidade foi definida como a quantidade da enzima requerida para produzir um aumento na absorvância a $420 \mathrm{~nm}$ igual a $0,1 \mathrm{em} 60 \mathrm{~min}$.

A concentração de proteínas foi determinada pelo método de Lowry, com as modificações propostas por PETTERSON [22].

\section{3 - Efeito do pH na atividade e estabilidade da protease}

A influência do $\mathrm{pH}$ sobre a atividade da protease foi avaliada na faixa de 6,0 a 10,0 com intervalo de 0,5 unidades. Para o preparo do substrato, foi utilizada uma mistura tamponante contendo tampão acetato de sódio, $\mathrm{pH} 5,5$; fosfato de sódio, pH 6,0-8,0; e tampão Tris/ $\mathrm{HCl}$, pH 8,5 a 10,0. Os valores de $\mathrm{pH}$ da mistura da reação foram ajustados com $\mathrm{NaOH}$ ou $\mathrm{HCl} 1 \mathrm{~N}$.

$\mathrm{O}$ pH ótimo foi determinado preparando-se o substrato (azocaseína 0,2\%) nas soluções tampões com diferentes valores de $\mathrm{pH}$ e incubando-o com $0,5 \mathrm{~mL}$ do extrato enzimático em banho-maria a $70{ }^{\circ} \mathrm{C}$ por $10 \mathrm{~min}$. Posteriormente, a atividade enzimática foi determinada conforme descrito anteriormente.

A estabilidade da protease a diferentes valores de $\mathrm{pH}$ foi avaliada incubando-se o extrato enzimático nos tampões anteriormente descritos, sem o substrato, por $2 \mathrm{~h}$ à temperatura ambiente. Após este tratamento, a atividade residual da protease foi determinada conforme descrito anteriormente.

\section{4 - Efeito da temperatura na atividade e estabilidade da protease}

A determinação da temperatura ótima para a atividade enzimática foi realizada incubando-se a mistura de reação ( $\mathrm{pH} 8,5$ ) em temperaturas que variaram de 30 a $100{ }^{\circ} \mathrm{C}$, com intervalos de $10^{\circ} \mathrm{C}$. Depois de 10 min de incubação em cada temperatura, a atividade enzimática foi analisada.

A estabilidade térmica foi avaliada incubando-se a enzima em temperaturas que variaram de 30 a $100{ }^{\circ} \mathrm{C}$, com intervalos de $10{ }^{\circ} \mathrm{C}$. Após duas horas de incubação, a atividade residual foi analisada à temperatura ótima da enzima, determinada anteriormente.

\section{5 - Compatibilidade e estabilidade da protease em vários detergentes comerciais}

Os detergentes Ariel ${ }^{\circledast}$, Ultra Biz ${ }^{\circledR}$, Cheer $^{\circledR}$, Tide $^{\circledR}$, Campeiro ${ }^{\circledR}$ e $\mathrm{Omo}^{\circledR}$ foram diluídos em água destilada a uma concentração final de $7 \mathrm{mg} / \mathrm{mL}$ para simular condições 
de lavagem. Em seguida, foram tratados termicamente a $100{ }^{\circ} \mathrm{C}$ por $15 \mathrm{~min}$, para inativar as enzimas que poderiam fazer parte da formulação dos detergentes. A protease, na concentração de $0,55 \mathrm{mg} / \mathrm{mL}$, foi adicionada na preparação do detergente e incubada a $70{ }^{\circ} \mathrm{C}$ por $1 \mathrm{~h}$ nesta solução. A cada $10 \mathrm{~min}$, foram retiradas amostras para determinação da atividade residual, tanto nos tratamentos quanto no controle (incubado sem detergente) [1, 23]. A influência do cálcio e da glicina, na estabilidade da protease junto aos detergentes, foi estudada adicionando-os à solução enzima detergente o $\mathrm{CaCl}_{2}(10 \mathrm{mM})$, glicina ( $\left.1 \mathrm{mM}\right), \mathrm{CaCl}_{2}(10 \mathrm{mM})+$ glicina $(1 \mathrm{mM})$. Os frascos foram incubados a $70^{\circ} \mathrm{C}$ por $1 \mathrm{~h}$ $\mathrm{e}$, em intervalos de $10 \mathrm{~min}$, amostras foram retiradas para determinação da atividade residual, que foi comparada com o controle realizado na ausência do detergente.

\section{3 - RESULTADOS E DISCUSSÃO}

\section{1 - Perfil do crescimento do microrganismo e atividade proteásica}

Bacillus sp. SMIA-2 cresceu e secretou proteases quando cultivado num meio de cultura contendo soro de leite, um resíduo das indústrias de laticínios (Figura 1). De fato, meios de cultura ricos em proteínas, como aqueles contendo o soro de leite, possuem indutores que levam à produção de proteases [24].

A atividade máxima da enzima (70 U/mg proteína) foi alcançada após $32 \mathrm{~h}$ de incubação do microrganismo, quando o crescimento já havia cessado e a cultura se encontrava na fase estacionária de crescimento. De acordo com WARD [30], os microrganismos do gênero Bacillus, geralmente, produzem maior quantidade de protease ao final da fase exponencial de crescimento e, embora a função destas enzimas ainda não seja bem conhecida, sua produção está correlacionada com uma elevada taxa de renovação de proteínas durante a esporulação.

A enzima permaneceu estável por $8 \mathrm{~h}$ e, após $40 \mathrm{~h}$ de crescimento, ocorreu uma queda drástica da sua atividade, indicando que a enzima sofreu um rápido processo de desativação, que é característico na produção de proteases por microrganismos [13].

A atividade máxima da protease encontrada neste trabalho foi superior àquela relatada por NASCIMENTO \& MARTINS [20] para o Bacillus sp. SMIA-2, cultivado num meio contendo citrato trissódico como única fonte de carbono. Além disso, o processo de desativação, que é típico da produção de proteases, foi retardado, em comparação ao encontrado pelos referidos autores.

\section{2 - Efeito do $\mathrm{pH}$ na atividade e estabilidade da protease}

A protease foi ativa em uma ampla faixa de $\mathrm{pH}$, apresentando máxima atividade (70 U/mg proteína) em torno de pH 8,0, como mostra a Figura 2. A atividade mais baixa da protease foi encontrada em pH 6,0 e 10,0, que foram os

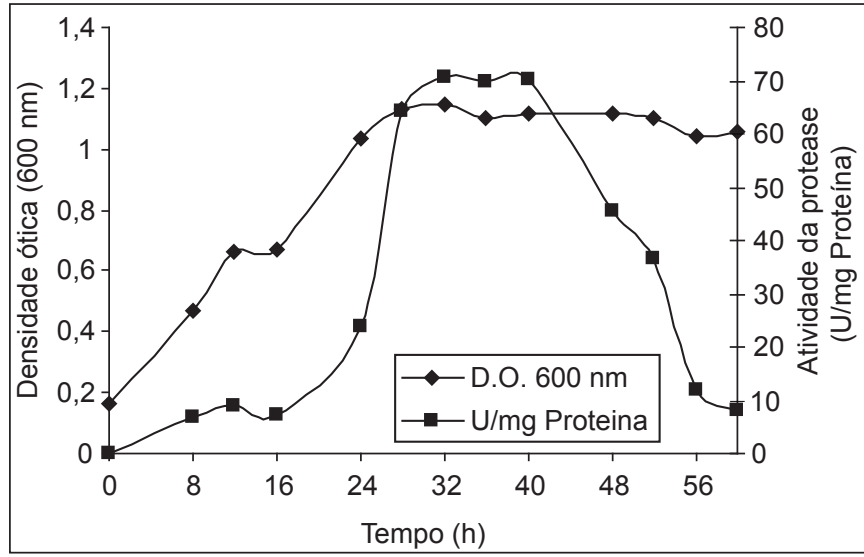

FIGURA 1 - Crescimento e atividade da protease secretada por Bacillus sp. SMIA-2, quando cultivado em soro de leite e água de maceração de milho por $60 \mathrm{~h}$ a $50{ }^{\circ} \mathrm{C}$.

valores mais extremos estudados. Resultados semelhantes relacionados ao $\mathrm{pH}$ ótimo de proteases foram encontrados por vários autores para diferentes microrganismos estudados. SOOKKHEO et al. [28] encontraram valores de pH ótimo de 8,5, 7,5 e 7,0, para três proteases ( $\mathrm{S}, \mathrm{N}$ e B, respectivamente) de Bacillus stearothermophilus TLS33. A protease $\mathrm{S}$ foi ativa em uma ampla faixa de $\mathrm{pH}$, sendo detectada cerca de $60 \%$ de atividade em pH 6,0 e 10,0 na presença de $5 \mathrm{mM}$ de $\mathrm{CaCl}_{2}$. Por outro lado, as proteases $\mathrm{N}$ e B mantiveram, relativamente, pouca atividade em pH 9,0. KIM et al. [16] encontraram, para a protease produzida por Bacillus stearothermophilus, valor de $\mathrm{pH}$ ótimo igual a 7,5, enquanto GERMANO et al. [8] encontraram um pH ótimo, para protease produzida por Penicillium sp., na faixa de 6,0 a 8,0. Além disso, FAHMY, ALI \& MOHAMED [5] encontraram $\mathrm{pH}$ ótimo igual a 4,0 para a protease produzida por Triticum aestivum.

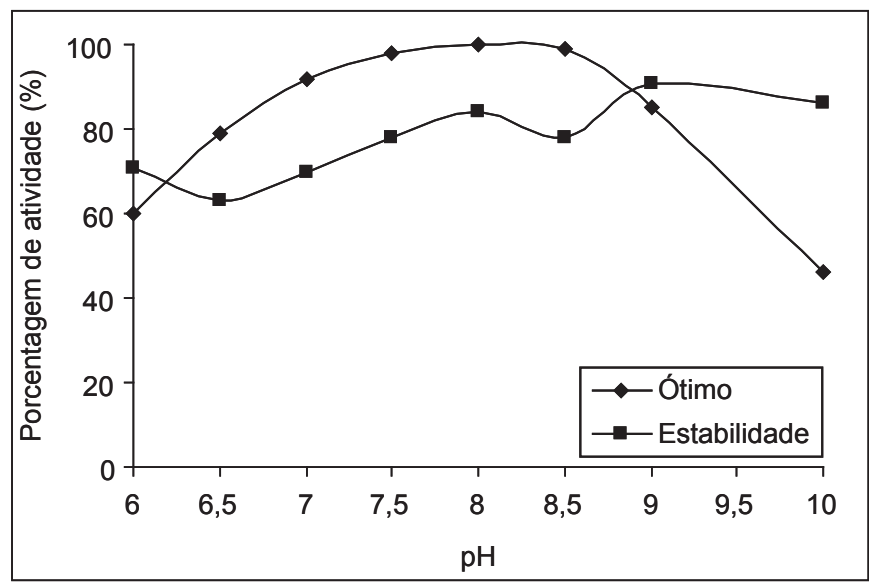

FIGURA 2 - Efeito do $\mathrm{pH}$ sobre a atividade e estabilidade da protease secretada por Bacillus sp. SMIA-2, em meio líquido contendo soro de leite e água de maceração de milho, por $36 \mathrm{~h} \mathrm{a} 50{ }^{\circ} \mathrm{C}$ ( $100 \%$ de atividade $=69,97 \mathrm{U} / \mathrm{mg}$ proteína $)$.

De acordo com BEG \& GUPTA [3], as proteases comerciais de origem microbiana, geralmente, possuem atividade ótima na faixa de $\mathrm{pH}$ que varia de 8,0-12,0, o que as torna 
de grande interesse para a utilização em formulações de detergentes, devido ao $\mathrm{pH}$ alcalino destes produtos.

O valor do $\mathrm{pH}$ da solução detergente é um importante parâmetro para determinar a viabilidade da aplicação de um determinado tipo de enzima. A atividade catalítica em valores elevados de $\mathrm{pH}(10,0-11,0)$, ou mesmo moderadamente elevados $(8,0-9,0)$, indica que a enzima é bastante viável para ser utilizada em detergentes. A Alcalase ${ }^{\circledR}$, enzima muito utilizada na indústria de detergentes, possui $\mathrm{pH}$ ótimo de atuação na faixa de 8,0-9,0 [10].

Em relação à estabilidade ao $\mathrm{pH}$, a enzima manteve $85 \%$ e $46 \%$ de sua atividade quando incubada por $1 \mathrm{~h}$ em $\mathrm{pH} 9$ e pH 10, respectivamente (Figura 2). GHORBEL, KAMOUN \& NASRI [9] encontraram valores semelhantes de estabilidade térmica para proteases de Bacillus cereus BG1, cuja estabilidade máxima foi alcançada em $\mathrm{pH}$ 8,0.

\section{3 - Temperatura ótima e estabilidade térmica}

A atividade da enzima aumentou com a elevação da temperatura, atingindo seu valor máximo a $70{ }^{\circ} \mathrm{C}$ (72 U/mg proteína), conforme mostrado na Figura 3. Esta temperatura foi superior àquela relatada por NASCIMENTO \& MARTINS [20] para o Bacillus sp. SMIA-2.

Nas temperaturas de $60{ }^{\circ} \mathrm{C}$ e $80{ }^{\circ} \mathrm{C}$, a enzima apresentou $72 \%$ e $67 \%$ de sua atividade, máxima, respectivamente. KIM et al. [16] encontraram resultados semelhantes para B. stearothermophilus, utilizando também a azocaseína como substrato. Este valor foi similar aos encontrados para outras proteases termoestáveis produzidas por Bacillus sp. [11].

JOO \& CHANG [13] encontraram temperatura ótima de 60 a $65{ }^{\circ} \mathrm{C}$ para uma protease produzida por Bacillus sp. I-312. De acordo com estes autores, a protease perdeu rapidamente a atividade quando incubada a $70{ }^{\circ} \mathrm{C}$. Duas proteases produzidas para a utilização na indústria de detergentes, a Alcalase ${ }^{\circledR}$ e a Esperase ${ }^{\circledR}$, possuem temperaturas ótimas de atividade por volta de $60{ }^{\circ} \mathrm{C}$, com rápida perda de atividade em temperaturas maiores que $70{ }^{\circ} \mathrm{C}[10]$.

Na presença do cálcio, a protease secretada pelo microrganismo em estudo foi mais estável. A contribuição deste íon, para a estabilidade da protease, foi mais efetiva em temperaturas mais elevadas, ou seja, na faixa de 60 a $90{ }^{\circ} \mathrm{C}$.

Quando incubada por $1 \mathrm{~h}$ a $40{ }^{\circ} \mathrm{C}$ na presença e ausência deste íon, a enzima manteve $92 \%$ e $91 \%$ de sua atividade, respectivamente. Na temperatura de $70{ }^{\circ} \mathrm{C}$, a enzima manteve $91 \%$ de atividade em presença de cálcio e $76 \%$ de atividade na sua ausência. Na temperatura de $80^{\circ} \mathrm{C}$, a contribuição do cálcio foi ainda mais pronunciada, e a enzima manteve $67 \%$ e $38 \%$ de sua atividade em presença e ausência deste elemento, respectivamente. Estes resultados demonstram que quanto mais elevada a temperatura, maior o efeito do cálcio na estabilidade da protease. Resultados similares foram encontrados por GESSESSE et al. [7], que relataram sobre a dependência do cálcio para a estabilidade térmica de uma protease produzida por Bacillus pseudofirmis, em temperaturas maiores que $50{ }^{\circ} \mathrm{C}$. De acordo com estes autores, a dependência do cálcio pelas enzimas está relacionada à presença deste metal como ligante do seu sítio ativo, levando à maior estabilização da enzima. Vários outros autores demonstraram o efeito do cálcio na estabilidade térmica de proteases à elevada temperatura. Eles atribuem este fato ao efeito protetor exercido pelo cálcio na manutenção da conformação ativa da enzima em elevadas temperaturas [3]. Segundo GODFREY \& WEST [10], mais de $75 \%$ de todas as enzimas conhecidas requerem a presença de íons metálicos para ativar sua atividade catalítica, sendo que concentrações extremamente baixas destes compostos podem ser suficientes para aumentar sua estabilidade térmica.

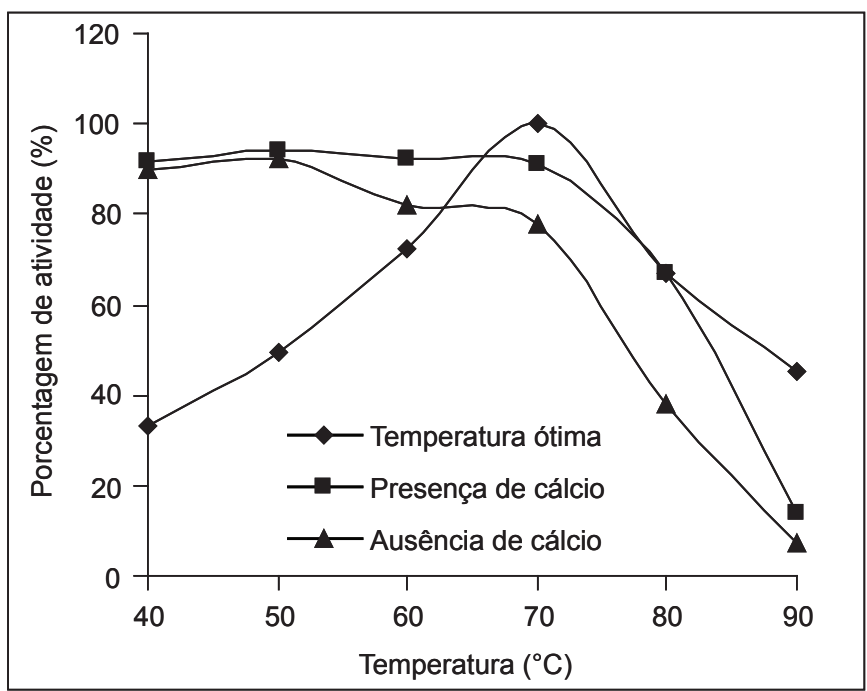

FIGURA 3 - Temperatura ótima e estabilidade térmica da protease secretada por Bacillus sp. SMIA-2, crescido em meio líquido contendo soro de leite e água de maceração de milho, a $50{ }^{\circ} \mathrm{C}$ por $36 \mathrm{~h}$ ( $100 \%$ de atividade $=72 \mathrm{U} / \mathrm{mgProteina})$.

A atividade enzimática em temperaturas elevadas favorece a utilização das enzimas em soluções detergentes, devido à utilização de temperaturas elevadas nos processos de limpeza. Entretanto, a elevada dependência do cálcio para a estabilidade térmica da protease não é desejável, quando o objetivo é sua utilização em soluções de detergentes, uma vez que estes compostos possuem elevada concentração de agentes quelantes como EDTA, o que poderá seqüestrar o cálcio e reduzir drasticamente a atividade da enzima [7].

\section{4 - Atividade da protease em detergentes comerciais}

A viabilidade da utilização da protease em formulações de detergentes foi verificada testando a sua compatibilidade com os seguintes detergentes comerciais: Ariel ${ }^{\circledR}$, Ultra Biz ${ }^{\circledR}$, Cheer $^{\circledR}$, Tide $^{\circledR}$, Campeiro $^{\circledR}$ e Omo $^{\circledast}$.

A protease manteve $64 \%$ e $50 \%$ de sua atividade quando incubada a $70{ }^{\circ} \mathrm{C}$ por 30 min com os detergentes Cheer ${ }^{\circledR} \mathrm{e}$ Tide $^{\circledR}$, respectivamente. A utilização da glicina, juntamente com íons cálcio, resultou em um aumento da estabilidade 
enzimática em todos os detergentes testados. Em presença dos detergentes Ultra bizz ${ }^{\circledR}$, Cheer ${ }^{\circledR}$ e Tide $^{\circledR}$, a enzima manteve aproximadamente $100 \%$ de atividade após $30 \mathrm{~min}$ de incubação a $70{ }^{\circ} \mathrm{C}$ (Figura 4).

Uma protease produzida por Bacillus cereus apresentou excelente estabilidade em detergentes, mantendo cerca de $80 \%$ de estabilidade após 1 h de incubação a 40 e $50{ }^{\circ} \mathrm{C}[2]$, enquanto que uma protease produzida por
Bacillus sp. SSR1 apresentou uma atividade residual de $70 \%$ na maioria dos detergentes estudados a $40{ }^{\circ} \mathrm{C}[26]$. Em temperaturas maiores que $40{ }^{\circ} \mathrm{C}$, esta enzima requereu a adição de agentes estabilizantes como cálcio, para que a enzima se mantivesse estável.

Uma protease produzida por Bacillus brevis mostrou compatibilidade com detergentes comerciais como Ariel, Surf excels, Surf Ultra e Rin, em presença de cálcio e glicina

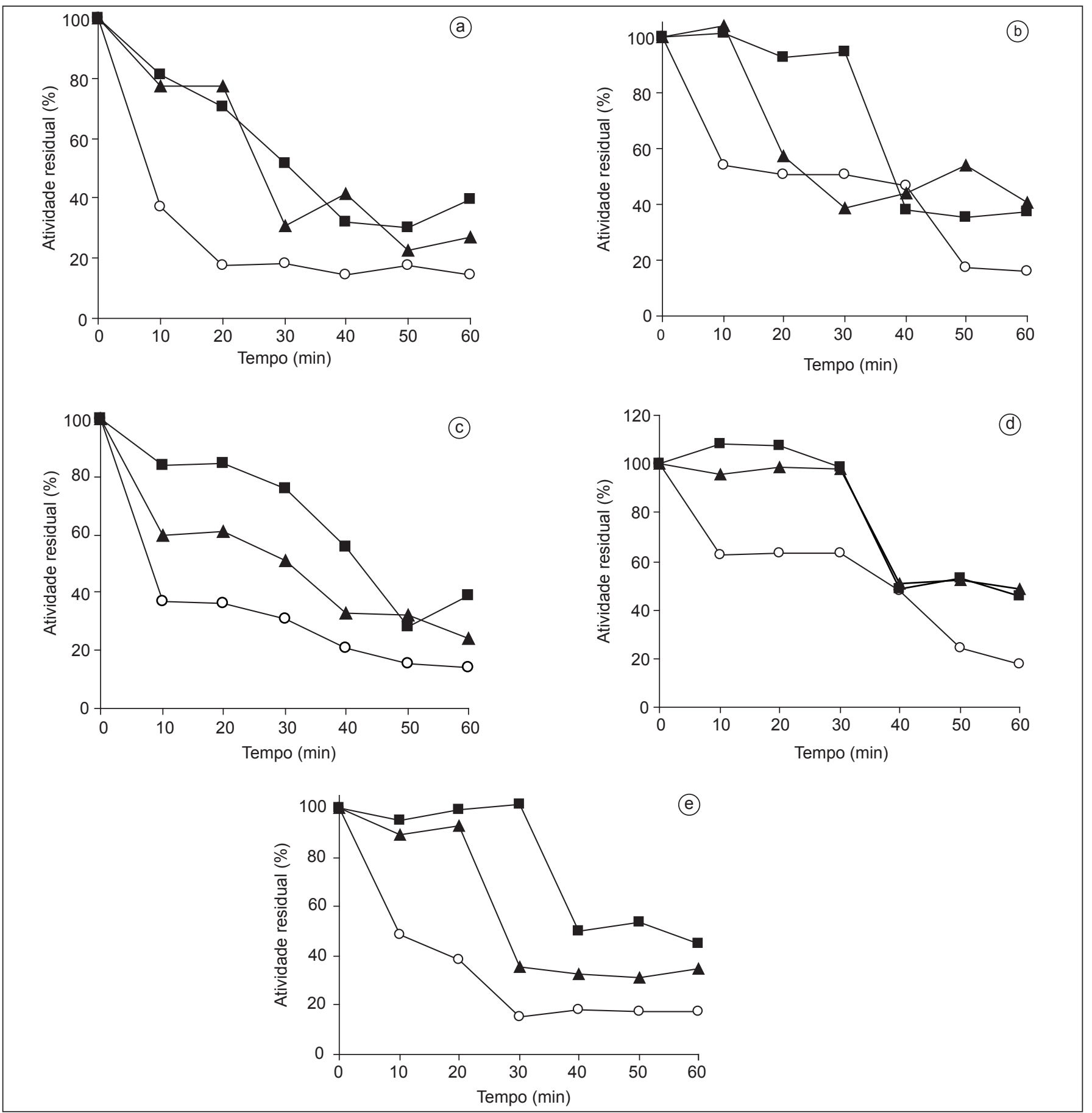

FIGURA 4 - Estabilidade da protease produzida por Bacillus sp. SMIA-2, em detergentes comerciais. (O) detergente e enzima, ( $\Delta$ ) detergente, enzima e cálcio, ( $\mathbf{\square}$ ) detergente, enzima, cálcio e glicina. Os detergentes estudados foram a) Ariel; b) Cheer; c) Omo; d) Tide $^{\circledast}$; e e) Ultra bizz. ( $100 \%$ de atividade $=64 \mathrm{U} / \mathrm{mg}$ de proteína $)$. Abreviação de minuto = min. 
[1]. Esta enzima manteve mais de $50 \%$ de atividade com a maioria dos detergentes testados após $3 \mathrm{~h}$ de incubação a $60{ }^{\circ} \mathrm{C}$. De acordo com GODFREY \& WEST [10], todas as proteases adicionadas em detergentes podem ser estabilizadas pela adição de certo nível de cálcio livre. Na maioria das vezes, cerca de 100 a 1000 ppm de cálcio são adicionados em detergentes líquidos que contêm proteases, para aumentar sua estabilidade. Ainda segundo estes autores, uma das formas de aumentar a estabilidade da enzima na presença de detergentes é evitar sua autólise, o que pode ser conseguido pela adição de inibidores reversíveis de proteases. Esses agentes podem inibir parcialmente a atividade das proteases por se ligarem ao seu sítio ativo. Porém, elas podem recuperar novamente sua atividade durante o processo de lavagem, no qual são utilizadas. A glicina, um dos inibidores reversíveis de proteases, é utilizada nos detergentes para esta finalidade.

\section{4 - CONCLUSÕES}

- Soro de leite e água de maceração de milho podem ser utilizados como substratos para a produção de proteases por Bacillus sp. SMIA-2;

- A temperatura e o $\mathrm{pH}$ ótimo para a atividade da enzima foram $70{ }^{\circ} \mathrm{C}$ e 8,0 , respectivamente; e

- A enzima apresenta excelente atividade em presença de alguns detergentes como Ultra bizz, Cheer e Tide. Nestes detergentes, a enzima mantém aproximadamente 100\% de atividade após 30 min de incubação a $70{ }^{\circ} \mathrm{C}$.

\section{5 - REFERÊNCIAS BIBLIOGRÁFICAS}

[1] BANERJEE, U. C., SANI, R. K., AZMI, W., SONI, R. Thermostable alkaline protease from Bacillus brevis and its characterization as a laundry detergent additive. Process Biochemistry v. 35, n. 1-2, p. 213-219, 1999.

[2] BANIK, R. M.; PRAKASH, M. Laundry detergent compatibility of the alkaline protease from Bacillus cereus. Microbiological Research, v. 159, n. 2, p. 135-140, 2004.

[3] BEG, Q. K.; GUPTA, R. Purification and characterization of an oxidation-stable, thiol-dependent serine alkaline protease from Bacillus mojavensis. Enzyme and Microbial Technology, v. 32, n. 2, p.294-304, 2003.

[4] BEG, Q. K.; SAXENA, R. K.; GUPTA, R. De-repression and Subsequent induction of protease syntesis by Bacillus mojavensis under fed bach operations. Process Biochemistry, v. 37, p. 1103-1109, 2002.

[5] FAHMY, A.; ALI, A. A.; MOHAMED, S. A. Characterization of cysteine protease from wheat Triticum aestivum (cv. Giza 164). Bioresource Technology, v. 91, p. 297-304, 2004.

[6] FEIJOO, G.; MOREIRA, M. T.; ROCA, E.; LEMA, J. M. Use of cheese whey as a substrate to produce mangenese peroxidase by Bjerkandera sp. BOS55. Journal of Industrial Microbiology e Biotechnology, v. 23, p. 86-90, 1999.

[7] GeSSESSE, A.; KAUL, R. H.; GASHE, B. A.; MATTIASSON, B. Novel alkaline protease from alkali- plhilic bacteria grow on chiken feather. Enzyme and Microbial Techology, v. 32, p. 519-524, 2003.

[8] GERMANO, S.; PANDEY, A.; OSAKU, C. A.; ROCHA, S. N.; SOCCOL, C. R. Characterization and stability of proteases from Penicillium sp. Produced by solid-state fermentation. Enzyme and Microbial Technology, v. 32, p. 246-251, 2003.

[9] GHORBEL, B., KAMOUN, A. S.; NASRI, M. Stability studies of protease from Bacillus cereus BG1. Enzyme and Microbial Technology, v. 32, p. 513-518, 2003.

[10] GODFREY, T.; WEST, S. Industrial Enzimology, $2 \mathrm{~d}$. Ed. Stockton Press Ed. US e Canadá, p. 609, 1996.

[11] HAMER, G.; MANSON, C. A. Fundamental aspects of waste sludge treatment: microbial solids biodegradation in an aerobic thermophilic semi-continous sistem. Bioprocess Engineering, v. 2, p. 69-77, 1987.

[12] HORIKOSHI, K. Alkaliphiles: Some Applications of Their Products for Biotechnology. Microbiology and Molecular Biology Reviews, v 43, p.735-750, 1999.

[13] JANSSEN, P. H.; PEEK, K; MORGAN, H. W. Effect of culture conditions on the production of a extracellular proteinase by Thermus sp. Rt41A. Applied Microbiology Biotechnology, v. 41, p.400-406,1994.

[14] JOO, H. S.; CHANG, C. S. Production of protease from a new alkalophilic Bacillus sp. I-312 grow on soybean meal: optimization and some properties. Process Biochemistry, v. 40, p.1263-1270, 2005.

[15] KANEKAR, P. P., NILEGOANKAR, S. S., SARNAIK, S. S., KELKAR, A. S. Optimization of Protease Activity of Alkaliphilic Bacteria Isolated From an Alkaline Lake in India. Bioresource Technology, v. 85, p. 87-93, 2002.

[16] KIM, Y. K.; BAE, J. H.; OH, B. K.; LEE, W. H.; CHOI, J. W. Enchancemente of protealytic enzyme activity excreted from Bacillus stearthermophilus for a thermophilic aerobic digestion process. Bioresource Technology, v. 82, p.157-164, 2002.

[17] KUMAR, C. G.; TAKAGI, H. (1999).Research review paper Microbial Alkaline proteases: from a bioindustrial viewpoint. Biotechnology Advances, v. 17, p. 561-594, 1999.

[18] MADIGAN, M.T.; MARTINKO, J. M.; PARKER, J. Brock Biology of Microorganism, 8 Edição, Ed. Pretince Hall, New Jersey, 986p, 1996.

[19] MAURER, K. H. Detergents proteases. Current opinion in Biotechnology, v. 15, p. 330-334, 2004.

[20] NASCimento, W. C. A. E MARTINS, M. L. L. Production and properties of na extracellular protease from thermophilic Bacillus sp. Brazilian Journal of Microbiology, v. 35, p. 91-96, 2004.

[21] NUNES, A. S.; MARTINS, M. L. L. Isolation, properties and kinetics of growth of a thermophilic Bacillus. Brazillian Journal of Microbiology, v. 32, p. 271-275, 2001.

[22] PETERSON, G. L. A simplification of the protein assay method of Lowry et al. which is more generally applicable. Analytical Biochemistry, v. 83, p. 346-356. 1977.

[23] PHADATARE, S. U.; DESHPANDE, V. V.; SRINIVASAN, M. C. High activity alkaline protease from Conidiobo- 
lus coronatus (NCL 86.8.20): Enzyme production and compatability with commercial detergents. Enzyme Microbiology Technology, v. 15, p. 72-76, 1993.

[24] ROMERO, F. J. ; GARCIA, L. A. ; SALAS, J. A. ; DÍAZ, M. ; QUIRÓS, L. M. Production purification and partial characterization of two extracellular proteases from Serratia marcessens grow in whey. Process Biochemistry, v. 36, p. 507-515, 2001.

[25] RIVAS, B.; MOLDES, A. B.; DOMINGUEZ, J. M.; PARAJÓ, J. C. Development of culture media containing spent yeast cells of Debaryomyces hansenii and corn steep licor for lactic acid production with Lactobacillus rhamnosus. International Journal of Food Microbiology, v. 97, p. 93 - 98, 2004.

[26] SINGH, J.; BATRA, N.; SOBTI, C. R. Serine alkaline protease from a newly isolated Bacillus sp. SSR1. Process Biochemistry, v. 36, p. 781-785, 2001.

[27] SISO, M. I. G. The biotechnological utilization of cheese whey: a review. Bioresource Technology, v. 57, p. 1-11, 1996.
[28] SOOKKHEO, B.; SINCHAIKUL, S.; PHUTRAKUL, S.; CHEN, S. T. Purification and characterization of the highly thermostable proteases from Bacillus stearothermophilus TLS33. Protein Expression and Purification, v. 20, p. 142-151, 2000.

[29] ZAMOST, B. L.; NIELSEN, H. K; STARNES, R. L. Thermostable enzymes for industrial applications. Journal of Industrial Microbiology, v. 8, p. 71-82, 1991.

[30] WARD, O. P. Proteolytic enzymes. In: M. Moo-Young Editor, Comprehensive Biotechnology, v. 3, p. 789-818. 1985.

\section{6 - AGRADECIMENTOS}

Os autores agradecem à FAPERJ (Fundação de Amparo à Pesquisa do Estado do Rio de Janeiro) pelo apoio financeiro e ao CNPq (Conselho Nacional de Desenvolvimento Científico e Tecnológico) pela concessão de uma bolsa de doutorado. 